\title{
Exploration of Organic Chemistry Experimental Course Assessment
}

\author{
Xia Chunhui, Zhang Hongguang, Xu Feng, Sun Ge, Fu Shuang ${ }^{\mathrm{a}, *}$ \\ College of Pharmacy, Qiqihar Medical University, Qiqihar 161006, China \\ a E-mail: fsjt1980@163.com \\ *Corresponding author
}

Keywords: organic chemistry experiment courses; assessment methods; evaluation methods; experiment report

\begin{abstract}
In view of the problems existing in the chemical experiments in universities and colleges in China, this paper has made reforms in the assessment of experimental courses, and summed up a theoretical and operational assessment method, established a set of just, fair and transparent scoring criteria. The criteria can improve the teaching quality of chemical experiment courses, stimulate the students' interest, team consciousness and practical ability, and correct the learning attitude and the sense of competition of students in attending chemistry experiment courses.
\end{abstract}

Chemistry experimental course is a basic experimental course in universities and colleges as well an important course for pharmacy majors after entering the universities. It marks the beginning of receiving systematic experimental methods and basic skill training for students, playing a crucial role in shaping good habits in the experiment and cultivating a scientific way of thinking. [1] The assessment of experiment results is a comprehensive assessment for problem discovery, analysis and solution in terms of experiment habit, knowledge as well as skills in the process. The authors have summarized a theoretical assessment method which is easy to implement in combination with the teaching conditions in the college during the years of teaching and research, exerting an ideal effect on the experimental course teaching in this university.

\section{Problems to be solved}

As the soul of chemistry course, the experiment is a macroscopic phenomenon in front of people, a mysterious power for exploring the micro-world, the major source for stimulating students' interests and their thirst for knowledge, as well as an important means to cultivate innovative thinking for students. Therefore, all universities and colleges have paid more attention to the reform of teaching methods of experimental courses, and provided more financial support, meanwhile, the running system and the assessment method of this course have been improved. [4-6] However, there are a variety of defects in the current experimental teaching. And the major defects are as follow: (1) The assessment method is single. The result is composed of experimental report, which cannot fully demonstrate the operation skills, way of thinking, and innovative abilities of students, failing to make a comprehensive and objective evaluation on students' knowledge. (2) The assessment criterion is not specific or unified. There is no specific and unified assessment criterion for teachers. They rather, evaluate according to their impression with casualty, thus, different teachers hold different assessment criteria for the same experiment and for different experiments, of course. [2] (3) The assessment results are not transparent or timely. The assessment is not conducted or announced on the site. So students do not know the specific rules, but feel confused about their results. Since they have no knowledge about their behavior and errors, they will make the same mistake the next time. (4) Students lack the sense of being a master. As long as they enter the classroom, they will be supervised and motivated by teachers, all their ideas are taught by teachers. Thus, they often perform well when the teacher looks at them. Such ideas fail to motivate students' sense of being master and responsibility. 


\section{Assessment method}

The establishment of a new assessment scheme can manifest students' real abilities and grades in a rational manner. The assessment is composed of usual results and final results. Take the organic chemistry as an example, there are 8 experiments on average for the pharmacy majors in general universities. The full score of each experiment is 10 point, so the total 80 point is the usual results, which include attendance, preview, discipline and health, experimental design, process and the report. While the final results are comprised by experimental operation and written examination with each being 10 point. The written examination includes various objective questions, and students need to choose two randomly and work out, as for the operation, students should complete the experiment independently by lot, whose results are given by teachers on the site.

\section{Assessment for usual results}

Each experiment is 10 point including preview, operation and report. Among them, the experimental report includes experiment objective, principle, original recording, results and discussion as well as a question for thinking. The objective and principle is to make students learn about teaching goals and key knowledge, form a theoretical summary and understanding, which will not be included into the assessment. While the experimental report focuses on the original record, results and discussion, and thinking question.

\subsection{Assessment on the experimental preview}

Teachers will raise around 10 questions for the experiment a week before the experiment, covering experimental principle, instrument, drugs, the properties of the drugs, precision and usage of the instrument, computing method, experimental process and prediction, and points for attention. These questions should be held to the student in charge of studies electronically to forward to other students. In this way, students will read the textbook with questions and make the literature review, which will help shape the students' habit of learning via the internet and improve their abilities in literature review. It is a necessary way to guide students to make researches for the future and achieve the targets of the experiment. And students are required to enter the classroom 10 minutes in advance for teachers checking the preview report of each student. The preview report shall include the experimental procedure, questions for answers, and experimental result prediction, finally, their questions and views on this experiment. In order to avoid copying, teachers should raise questions randomly in ten minutes at class, and students write the experimental principles and computing process orally or on the blackboard. According to the answering and the preview, teachers will make their assessment. For those with serious attitude, proposing wonderful questions or suggestions, teachers can add points appropriately. This method can prevent students from copying the textbook, correct their attitude to the experimental courses.

\subsection{Assessment on the experimental operation}

The experimental course is mainly to enhance the operational abilities, abilities for discovering and solving problems of students, therefore, the experimental operation accounts for $40 \%$ of the results, which requires serious attitude, teamwork spirit, and timely experimental recording. In the process, teachers will provide guidance for each group, deduct points for those with unserious attitude, criticize the instrument usage that is not standard and give their feedback timely. For instance, in the determination of the equilibrium constant of acetic acid, when calibrating the acetic acid, some students use measuring cylinder rather than pipette to place $25 \mathrm{ml}$ of acetic acid in the conical flask, add sodium hydroxide solution into the burette standing on the chairs, shake the conical flask until the sodium hydroxide solution flows in stream and turns color. All these are wrong operations. And some even play games on the mobile phone, speak loudly or discuss other things outside the experiment. Thus, 0.5 point will be subtracted from each error. If an experiment has eight errors, the point will be reduced to zero. The experimental operation assessment represents the result of the group, which often includes 2 students. Thus, one's error will reduce the overall 
results of the group. If a student conducts experiment while the other plays or chats, they will face pressure. While this method can increase their cooperation and team spirit, promote them to supervise each other, offer help and shoulder responsibilities actively.

\subsection{The assessment on the experimental report}

Before the organic experiment courses, teachers will make preparation jointly and design the forms and contents of the experimental report. Then, the report will be handed to the office of academic affairs to print and bind, and finally, it will be distributed to each student.

In order to form an honest attitude to the science and research and shape a sound experimental habit, it is important to record the original data. In the teaching research, it is found that, if students record their data on a paper or on the preview report, they will be easily lost or forged. Therefore, students are required to record data on the back of the front page of the experimental report. After handing the report, teachers will focus on the original record to see if there is a modification. If there is, teachers shall ask for reasons. When the students make rational explanation and the data are realistic, teachers will sign their name or seal. If the data are obtained by copying or forging, the point for the part and the point for result and discussion will be zero. As the experimental results are the copies of the original data, they must be consistent, otherwise, they will be regarded as zero. In some cases, students and teachers will analyze the reasons together. As long as the operation is rational and proper, it will obtain good results. In addition, the discussion is mainly for the deviation or big error in the phenomenon, yield and data. If the explanation is not rational failing to discover the roots of the errors, points will be cut accordingly. If the explanation is rational with deep understanding for the experiment, it will receive good results.

The thinking question is to deepen the understanding for the instrument operation, experimental phenomenon, and computing process. Teachers will assign points according to the difficulty of each question, mark the points for deduction and correct errors to make students know the error, convince and accept the results.

\subsection{Assessment Method}

In order to ensure just, fair, and transparent experimental results, motivate students, make students supervise each other, realize self-consciously, self-discipline and self-evaluation, a method combining self-evaluation, third-party evaluation, with teacher's evaluation will be adopted. The self-evaluation is to give students' own grade on the preview, operation and original record. The third-party evaluation is for a party to make an objective evaluation on the other party in light of operation and original recording on the opposite that shares the drugs.

Teacher's evaluation is the evaluation on each experiment item, and the operation scores of each group are given according to the cooperation ability, experimental attitude and standardization. Thus, group members share a grade. Meanwhile, teachers will judge if the self-evaluation, third-party evaluation are rational, realistic and just, and then give their evaluation for each student. And the evaluation items and criterion are shown in table 1 . As shown in table 1, the self-evaluation and third-party evaluation will be given, and teachers will give their grades in the last line of the table. The average point of the three items is the final result.

Table 1 Criterion for evaluation of Teachers

\begin{tabular}{|c|c|c|c|c|c|c|c|}
\hline Judge & $\begin{array}{l}\text { Student } \\
\text { number }\end{array}$ & Preview(1) & Operation(4) & $\begin{array}{l}\text { Original } \\
\operatorname{data}(2)\end{array}$ & $\begin{array}{l}\text { Result and } \\
\text { discussion(2) }\end{array}$ & $\begin{array}{l}\text { Thinking } \\
\text { question(1) }\end{array}$ & $\begin{array}{l}\text { Total } \\
\text { point }\end{array}$ \\
\hline Self-Evaluat & & & & & & & \\
\hline $\begin{array}{l}\text { Third-Party } \\
\text { Evaluation }\end{array}$ & & & & & & & \\
\hline $\begin{array}{l}\text { Teacher's } \\
\text { Evaluation }\end{array}$ & & & & & & & \\
\hline
\end{tabular}




\section{The assessment of final examination}

After finishing the experimental courses, the students are organized to take the final exam, including the final written test and the final experiment. According to the situation of the unit, the examination is divided into two test centers, each of which has four experiments, two teachers, and each teacher is responsible for the assessment of two experiments. Students in each class will draw lots to decide which examination room to enter, and then determine the content of the experiment in the same way.

\subsection{Assessment on the final written examination}

Key points in each experiment should be printed on the top of a card for students to choose after entering the examination room. Then, they will get a white paper and write down their answers to the theoretical questions on the card for teachers, who will give their score on the spot. The test is then performed according to the requirements below the card.

\subsection{Assessment on the final experiment}

Each experimental operation is segmented into 10 minutes, and to ensure the integrity of each segment, the experiment content is printed at the bottom of the card, and experimental operation is performed according to the requirements on the card, which is under teachers' supervision in the whole process and is evaluated.

\section{Conclusion}

The authors, by comparing the assessment methods of chemistry experiments, divided the students in the same grade into the control group and the experimental group. As the data of final examination show, by applying this method, students get rational results, and their enthusiasm for study is mobilized, their consciousness of study and self-discipline have been improved. The statistics and the results will be published in the future. Taking organic chemistry experiment as an example, the paper expounded the detailed assessment system and methods, which had achieved ideal impact on the teaching. This method provided a reference for experimental course reform for other universities and colleges, being of high applied value and a bright prospect.

\section{Acknowledgement}

The paper is sponsored by Qiqihar Medical University (JY20141017)

\section{References}

[1] Wang Feng, Huang Wei, Zhu Honglong, et al. Exploration of the establishment of design experiments in inorganic chemistry experiment teaching [J]. Teaching research, 2015, 38 (3):94-97.

[2] Zhou Zuxin, Wang Aimin, Cheng Liping, et al. Exploration on the assessment of basic chemistry experiment course [J]. Chemical education, 2014 (4):31-33.

[3] Xia Chunhui, Fu Shuang et al. Medical chemistry experiment. 2nd edition. Beijing: science press, 2016: 73-77.

[4] Li Xiangqing, Kang Shizhao, Mu Jing, et al. Discussion on the reform of the experimental teaching of inorganic chemistry in universities [J]. Chemical higher education, 2011(5):24-26.

[5] Hong Xiaobo, Zhou Guoquan, Fang Jianghua, et al. Six principles of engineering capability cultivation of excellent engineers [J]. Education exploration, 2012(11):56-58.

[6] Niu Haijun, Bai Xuduo, Zhang Yanhong. Experimental teaching method in cultivating students' innovative ability $[\mathrm{J}]$. 